\title{
Acessibilidade e deficiência na universidade: política de recursos humanos ${ }^{1}$
}

\author{
Carlos Eduardo Candido Pereira ${ }^{2}$ \\ Jose Luis Bizelli ${ }^{3}$ \\ Lúcia Pereira Leite ${ }^{4}$
}

\section{Introdução}

A história da pessoa com deficiência é marcada por fatores de exclusão social (MAZZOTA, 2005). Tal cenário passa por alteraçôes no século XX - sobretudo no período pós-guerras ${ }^{5}$ - culminado com a Declaração Universal do Direito do Homem (ONU, 1948).

1 Pesquisa vinculada ao projeto em rede "Acessibilidade no Ensino Superior", da Faculdade de Filosofia e Ciências da Universidade Estadual Paulista (FFC-Unesp), Marília/ SP, financiada pelo Programa Observatório da Educação (Obeduc), da Coordenação de Aperfeiçoamento de Pessoal de Nível Superior (Capes) - Edital n. 49/2012.

2 Unesp - Universidade Estadual Paulista. Programa de Pós-Graduação em Educação Escolar da Faculdade de Ciências e Letras. Araraquara - São Paulo - Brasil. Doutorando. Bolsista Obeduc/Capes.

3 Unesp - Universidade Estadual Paulista. Programa de Pós-Graduação em Educação Escolar da Faculdade de Ciências e Letras. Araraquara - São Paulo - Brasil. Pesquisador do projeto em rede "Acessibilidade no Ensino Superior" (Obeduc/Capes).

4 Unesp - Universidade Estadual Paulista. Programa de Pós-Graduação em Psicologia do Desenvolvimento e Aprendizagem da Faculdade de Ciências. Bauru - São Paulo - Brasil. Pesquisadora e colaboradora na coordenação do projeto em rede "Acessibilidade no Ensino Superior" (Obeduc/Capes).

5 Bobbio (2004) pontua que, apesar do período das grandes guerras ter sido superado, os confrontos localizados, as cruzadas de extremistas e o terrorismo ainda estão presentes em nossa época. 
$\mathrm{Na}$ atualidade, é inegável reconhecer que pessoas com deficiência obtiveram reconhecimento de sua condição, sobretudo, por meios legais. A década de 1990 foi auspiciosa para conquistas de direitos por parte das pessoas com deficiência. A Conferência Mundial de Educação para Todos, em Jomtien, Tailândia (1990) e a Declaração de Salamanca, Espanha (1994), debateram em âmbito internacional a condição de acesso escolar a todas as pessoas indistintamente.

O Brasil - como signatário das conclusôes e determinaçôes retiradas dos eventos mencionados - buscou mudanças nas políticas educacionais e em outras áreas ligadas ao cuidado da pessoa com deficiência; por exemplo, na arquitetura e na engenharia das construçóes.

Os limites e as possibilidades (BIZELLI, 2013) que foram dados para o avanço na elaboração das políticas inclusivas cristalizaram-se na legislação pertinente. Cabe, portanto, investigar com cuidado a bibliografia e a legislação que trata do ingresso e da permanência de servidores públicos com deficiência na universidade.

\section{Políticas em prol das pessoas com deficiências: escola e trabalho e sua relação}

No Brasil, quando se pensa na regulação do Sistema Educacional, a maior conquista foi a Lei de Diretrizes e Bases da Educação Nacional, Lei Federal n. 9394/1996 (BRASIL, 1996) a qual dedicou um capítulo especial composto de três artigos (58, 59 e 60) à Educação Especial e previu a matrícula das pessoas com deficiências na escola regular.

Num universo onde as mudanças tecnológicas e legislativas impactam em todo o sistema social, temos na relaçáo que se estabelece entre escola e trabalho um fator primordial para o desenvolvimento da sociedade. Nesta direção, segundo Miranda (2006, p.161):

Cabe à escola oferecer apoio para que o aluno desenvolva as competências necessárias para a realização do seu projeto de vida, assegurando-lhe as condiçóes para enfrentar os grandes desafios do mundo do trabalho.

Por ser o mundo do trabalho espaço no qual a mão de obra oriunda da escola é absorvida, cabe destacar a importância dessa relação. É sabido que a escola, de per si, não é suficiente para preparar o ingresso do cidadáo no mercado de trabalho, já que ele necessita percorrer trajetórias complementares, com cursos diversos em escolas técnicas, profissionalizantes etc.

Se pensarmos que a LDB é de 1996, um cidadão que iniciou seus estudos sob a égide da nova legislação está chegando agora ao mercado de trabalho formal, tendo passado pela universidade. É evidente que, ao considerarmos nosso público-alvo, seria possível imaginar que um contingente significativo já ingressara na escola anteriormente à Lei. 
No que tange ao trabalho, Sassaki (2006) aponta quatro períodos de alteração do espaço laboral para receber pessoas com deficiência. São eles: exclusão quando não se tinha conhecimento das possibilidades para o trabalho da pessoa com deficiência -; segregaçáo - quando as pessoas com deficiências tinham reconhecimento de suas capacidades, porém, trabalhavam em outros espaços que não o do trabalho formal -; integração - quando as pessoas com deficiências eram postas no trabalho com outras pessoas, mas com restriçóes -; e inclusão - momento em que o trabalho se adaptou às necessidades das pessoas com deficiências.

O universo do mercado de trabalho é diferente do universo escolar. Compreender aquele talvez ajude a entender melhor a escola real, facilitando o exercício de pensá-la no futuro desejável. Ainda no inicio da década de 1990, foi promulgada a Lei Federal n. 8.213/1991 (BRASIL, 1991) que estabelece cotas compulsórias a serem respeitadas pelos empregadores na admissão e na demissão de pessoas com deficiências.

A referida lei é conhecida também como Lei de Cotas e estabelece no artigo $93^{\circ}$ que as empresas com mais de 100 empregados têm a necessidade de contratar pessoas com deficiências. Assim, as empresas devem contratar pessoas com deficiências na ordem apresentada no Quadro 1.

Quadro 1. Índice de referência para porcentagem de contratação de pessoas com deficiências

\begin{tabular}{|l|l|}
\hline De 100 a 200 empregados & $2 \%$ de vagas destinadas às pessoas com deficiência \\
\hline De 201 a 500 empregados & $3 \%$ de vagas destinadas às pessoas com deficiência \\
\hline De 501 a 1000 empregados & $4 \%$ vagas destinadas às pessoas com deficiência \\
\hline De 1001 ou mais empregados & $5 \%$ vagas destinadas às pessoas com deficiência \\
\hline
\end{tabular}

Fonte: Artigo 93, Lei Federal n. 8.213 (BRASIL, 1991).

Se analisarmos a percentagem apresentada, caberia perguntar aqui se a lei vale também para os órgãos públicos. Antes de responder, é preciso compreender qual a natureza dos órgãos públicos, ou seja, a especificidade da administração que rege o setor público. Segundo Farah (2013), a administração pública teve origem como campo de estudos, quando, nos Estados Unidos da América, há cerca de um século, servidores públicos que atuavam na administração pública moderna passaram a ser observados. Tratava-se de uma ciência nova.

Complementando isto, Gugel (2006, p.67) aponta que a administração pública deve estar organizada para realizar todos os serviços que lhe estão afetos, com primado no interesse público, visando a satisfação dos direitos de igualdade. Diante da legislação em vigor, ${ }^{6}$ Farah (2013) apresenta a administração pública da seguinte maneira:

6 Decreto-Lei n. 200/1967. 
1. administração direta ou centralizada: é constituída dos serviços integrados na estrutura da Presidência da República e dos ministérios. No âmbito estadual, constitui-se do Gabinete do governador e das Secretarias de Estado. No município, do Gabinete do prefeito e das Secretarias Municipais;

2. administração indireta ou descentralizada: é aquela atividade administrativa, em que o Estado descentraliza o desempenho da atividade para outras pessoas jurídicas de direito público ou privado. São tipos desta administração as autarquias, ${ }^{7}$ as empresas públicas, ${ }^{8}$ as sociedades de economia mista, ${ }^{9}$ e as fundaçóes. ${ }^{10}$

Vejamos então: a lei vale também para os órgãos públicos? Sim, a lei vale também para a administração pública.

\section{Ingresso da pessoa com deficiência no setor público}

Para o ingresso no serviço público, além da questão legal, é condição para as pessoas com ou sem deficiência a realização de concurso público. Para Meirelles (2001, p.403-404), concurso público é:

Meio técnico posto à disposição da Administraçáo Pública para obter-se moralidade, eficiência e aperfeiçoamento do serviço público e, ao mesmo tempo, propiciar igual oportunidade a todos os interessados que atendam aos requisitos da lei, fixados de acordo com a natureza e a complexidade do cargo ou emprego, consoante determina o Art. 37, \$ II da CF.

7 Autarquia é a forma de descentralização administrativa, através da personificação de um serviço retirado da administração centralizada e, por essa razấo, à autarquia só deve ser outorgado serviço público típico e não atividades industriais ou econômicas, ainda que de interesse coletivo.

8 Entidade dotada de personalidade jurídica de direito privado, com patrimônio próprio e capital exclusivo da União, criada por lei para a exploração de atividade econômica, que o governo seja levado a exercer, por força de contingểncia ou conveniência administrativa, podendo revestir-se de qualquer das formas admitidas em direito. Exemplo de empresas públicas: Correios e Caixa Econômica Federal.

9 Entidade dotada de personalidade jurídica de direito privado, criada por lei para a exploraçáo de atividade econômica, sob a forma de sociedade anônima, cujas açôes com direito a voto pertençam, em sua maioria, à União ou a entidade da administração indireta. Exemplo: Banco do Brasil e Petrobrás.

10 Entidade dotada de personalidade jurídica de direito privado, sem fins lucrativos, criada em virtude de autorizaçáo legislativa para o desenvolvimento de atividades que não exijam execução por órgão ou entidades de direito público, com autonomia administrativa, patrimônio próprio gerido pelos respectivos órgãos de direção, e com funcionamento custeado por recursos públicos e de outras fontes, com objetivos geralmente voltados para o ensino, pesquisa e atividades culturais. Seu estatuto deve ser registrado e inscrito no Registro Civil de Pessoas Jurídicas. Exemplo: IBGE. 
No Brasil, o estabelecimento de normas gerais para a abertura e realização de concursos públicos é de competência do Ministério de Estado, Planejamento e Gestão, conforme decreto n. 4.175/2002, revogado pelo decreto n. 6944/2009 (BRASIL, 2009), respaldado por órgãos semelhantes em âmbitos estaduais e municipais.

O funcionamento da abertura de concurso ocorre da seguinte maneira. Primeiro, por pedido elaborado por órgão ou entidade interessado ao Ministério do Planejamento, Orçamento e Gestão (ou órgão responsável na esfera estadual e municipal). Tal pedido deve conter a descrição do processo de trabalho e a relevância das atividades no órgáo ou entidade, o número de vagas disponíveis em cada cargo ou emprego público; o quadro de movimentação de pessoal nos últimos anos com desligamentos, aposentadorias, dentre outros. Após isso, o Ministério, com base na compatibilização entre as necessidades da administração, as prioridades governamentais e a disponibilidade dos recursos orçamentários defere o pedido e libera para que a administração pública, por meio de órgãos e entidades, proceda à realização do concurso.

O passo seguinte é a liberação do edital, que obrigatoriamente deve sair no Diário Oficial, sob pena de nulidade (GUGEL, 2006). Após sair o edital, o concurso é considerado válido.

O edital apresenta quais são as etapas ou fases do concurso público. Pela Constituiçẫo Federal de 1988, Art. 37, II (BRASIL, 1988), deverá ser de provas e títulos e realizado em diferentes etapas. Dentre as fases do concurso pode-se citar: provas de conhecimentos gerais, provas de conhecimento específico, avaliação de títulos, prova de esforço físico ou outras habilidades (caso a vaga assim requeira, por exemplo: motorista). Tais fases podem ser de cunho classificatório ou eliminatório.

Vale ressaltar que os concursos públicos não podem requisitar como etapa prévia os exames psicotécnicos, pois a avaliação de capacidade - integral, física, emocional, sensorial, produtiva - será feita durante o estágio probatório (GUGEL, 2006).

Caberia aqui outra questão: as cotas para pessoas com deficiências não é uma forma de discriminação? A resposta é: Sim! Entretanto, os juristas tratam o termo como uma "discriminação positiva" para se chegar ao "direito de igualdade".

Para Canotilho (1998, p.399), o "direito de igualdade" correlaciona a igualdade e a discriminação. Destarte, veda a discriminação enquanto resultado de ato que proporciona tratamento desigual e indica a discriminação para compensar desigualdades de oportunidade e tratamento. Em adendo a essa ideia, Gugel aponta que (2006, p.49):

A discriminação positiva em favor das pessoas com deficiências está em perfeita consonância com os objetivos fundamentais estabelecidos na Constituição que impóe a ação positiva do Estado de erradicar a pobreza, a marginalização e reduzir as desigualdades sociais, regionais e promover o bem-estar de todos, sem preconceitos de origem, raça, sexo, cor, idade e quaisquer outras formas de discriminação, oferecendo meios institucionais diferenciados para o acesso de grupos de excluídos do sistema e, 
portanto, viabilizar-lhes o gozo do exercício de direitos fundamentais, alcançando, assim, a "igualdade real".

A reserva de cargos e empregos públicos é uma forma direta de discriminação, mas positiva. Trata-se de meio para que pessoas com deficiências recuperem o tempo de exclusão. Com isso, participar de concurso público lhes garante, dentre outros aspectos: adaptação de provas diante da deficiência declarada, em igualdade de condição com os demais candidatos; isto tem consequências no conteúdo, nos critérios de aprovação, no horário, no local de aplicação de provas e na nota mínima exigida.

Salienta-se que quando se refere a cargos ou a geração deles, há uma proximidade entre escolaridade, qualificação e mercado de trabalho. Isto porque esses fatores estão interligados num processo dinâmico e contínuo, na medida em que pessoas buscam elevação de escolaridade e qualificação profissional para atender ao mercado de trabalho, este último constituindo-se como herói e vilão ao criar, suprimir, recriar, abrir e ofertar novos postos de trabalho (CHIAVENATO, 2004).

A decisão da pessoa com deficiência a concorrer ao cargo público não é simples. De acordo com Gugel (2006, p.23-24):

A participação desse candidato em concurso público, desde a inscrição até a nomeação, não raro, é conflituosa [...] Isto acontece porque, não obstante os princípios constitucionais de pleno acesso, concurso público e a reserva de cargos e empregos, a Administração Pública em todos os níveis (federal, estadual e municipal) não está preparada para receber este cidadão em seus quadros.

Este despreparo mencionado pela autora consolida-se em editais confusos ou pouco esclarecedores à margem das normas vigentes como:

- não aferimento de servidores e empregados públicos em seus quadros;

- não estabelecimento de meta para cumprimento da reserva de vagas de empregos públicos;

- falta de respeito às provas e locais de realização de provas adaptados;

- falta de respeito à ordem de classificação, compatibilizando lista geral e específica;

- não disponibilização de cargos e empregos públicos sob a justificativa de aptidáo plena ou incompatível com a deficiência;

- falta de apoio especial durante período de estágio probatório. (GUGEL, 2006)

Tais situações e outras existentes não são harmônicas ao princípio de razoabilidade $^{11}$ e interesse público que norteia a administração pública; logo, impede a inclusão.

11 O princípio da razoabilidade é uma diretriz de senso comum, ou mais exatamente, de bom senso, aplicada ao Direito. Esse bom senso jurídico se faz necessário à medida 
Os editais devem apresentar a descrição das atribuiçóes e tarefas do cargo ou emprego público. Isso para pessoas com ou sem deficiência, para que permita ao candidato se decidir quanto a se inscrever e a prestar o concurso, uma vez que aprovado estará habilitado para seguir as regras e funções apresentadas.

No que tange à inscrição, os editais devem apresentar o quantitativo de vagas reservadas às pessoas com deficiências, tal como atribuiçóes e tarefas do cargo, previsão de adaptação das provas, curso de estágio probatório e laudo médico que atesta a deficiência. Este último será exigido ao candidato no ato da inscrição. Nele se atesta o grau e a espécie da limitação com base no CID. ${ }^{12}$ A pessoa com deficiência, todavia, no ato da inscriçấo deve apontar sua necessidade indicando condição para tratamento diferenciado.

Ainda sobre a inscrição em concurso público, o Decreto n. 3.298 (BRASIL, 1999) aponta que pessoas com deficiências têm garantia reservada de, no mínimo, 5\% das vagas perante a classificação obtida. Por exemplo, se houver dez vagas, uma deverá ser de pessoa com deficiência. A percentagem fracionada daria um resultado de 0,5. Quando isso acontece, sempre se arredonda para cima, pois não existe meia pessoa.

No que tange às provas, sua aplicação e realização, a lei - Decreto n. 3.298 (BRASIL, 1999) - também garante que sejam respeitadas as especificidades dos candidatos com deficiência, pois assim garante-se a igualdade de oportunidades. Para isso, a organização do concurso deve garantir serviços de apoio especial e de animais - no caso do cão-guia para cegos -, intérpretes e instrumentos/aparelhos auxiliares com o objetivo de proporcionar a igualdade de direitos. O local das provas também deve respeitar a lei de acessibilidade n. 10.098 (BRASIL, 2000), inibindo barreiras arquitetônicas e de comunicação.

O concurso pode ser realizado em etapas ou pela soma de pontos em mais de uma etapa. Após a realização do concurso, a classificação deverá ser publicada em Diário Oficial, com a relação de aprovados.

No que concerne aos candidatos com deficiências classificados, o resultado deverá estar disponível em duas listas; uma geral, contendo a relação de todos os classificados e outra denominada "lista especial", contendo a classificação apenas dos candidatos com deficiência. Primeiro são chamados os aprovados da lista geral e depois os da lista especial observando-se a regra do percentual mínimo de 5\%.

Segundo Gugel (2006), se a convocação inicial for de cinco candidatos, convocam-se os quatro primeiros classificados da lista geral e o quinto convocado

que as exigências formais que decorrem do princípio da legalidade tendem a reforçar mais o texto das normas, a palavra da lei, que o seu espírito. Enuncia-se com esse princípio que a administração, ao atuar no exercício de discrição, terá de obedecer a critérios aceitáveis do ponto de vista racional, em sintonia com o senso normal de pessoas equilibradas e respeitosas das finalidades que presidiram a outorga da competência exercida. Vide princípio da proibição do excesso.

12 Classificação Internacional de Doenças e Problemas Relacionados à Saúde. 
será o primeiro da lista especial. Se um candidato com deficiência já estiver entre os quatro primeiros, não deve ser computado para a reserva, chamando na quinta convocação o segundo da lista especial. Caso a administração pública decida que para o primeiro provimento seja destinada apenas uma vaga, esta deve ser preenchida pelo candidato que consta em primeiro lugar da lista geral; a próxima convocação, no entanto, deverá ser destinada ao primeiro candidato da lista especial. Caso náo tenha candidatos com deficiência inscritos ou aprovados, não há necessidade de lista especial.

O candidato aprovado será nomeado e, no caso do candidato com deficiência, o administrador deve considerar a adaptaçáo do local de lotação ou da contratação. O candidato cumprirá um estágio probatório de 3 anos.

Por último, cabe ao servidor realizar exame admissional que é realizado por médico do trabalho que fará uma anamnese ocupacional, exame físico, mental e complementar que poderá indicar necessidade de algum apoio especial ou mesmo indicar impossibilidade de atuaçáo laboral futura, o que justificaria pedido de aposentadoria. Esse exame poderá ser realizado em parceria com uma equipe multiprofissional, que pode, inclusive, acompanhar o servidor no exercício do trabalho.

\section{No setor público}

Cabe ressaltar que, em serviço público, a pessoa com deficiência, tal como os demais servidores públicos, se insere dentro de um universo estritamente burocrático. O setor público possibilita a seu servidor uma autonomia reflexiva, porém, coloca diariamente em confronto a sua função administrativa e burocrática com a sua individualidade. "Eles entram em crise, comandados pelas dificuldades de reposição da burocracia: o modelo burocrático não adere mais à realidade, atrita-se com ela" (NOGUEIRA, 2005, p.33).

Fica claro que, apesar da autonomia reflexiva, o servidor é limitado por procedimentos específicos que evidenciam apenas a burocracia em detrimento de outros

aspectos. É como se as relaçóes no trabalho fossem pautadas, cada vez mais, pela formalidade. Concordamos com o autor citado quando, ao apresentar o quadro a seguir, apresenta-se um novo perfil de servidor público: valorizado individualmente, respeitado na sua integridade humana e motivado na função/cargo.

Pela comparação dos perfis apresentados a seguir, ao ampliar esse quadro comparativo à universidade pode-se observar um sofrimento organizacional dos envolvidos na estrutura universitária. Vale ressaltar também que aos professores a função de ensino não é a única atribuição, pois cada vez mais é exigido que deem conta de estruturas burocráticas com reuniôes departamentais, de conselho etc. 
Quadro 2. Diferenciação do perfil burocrático e da individualidade dos profissionais na contemporaneidade

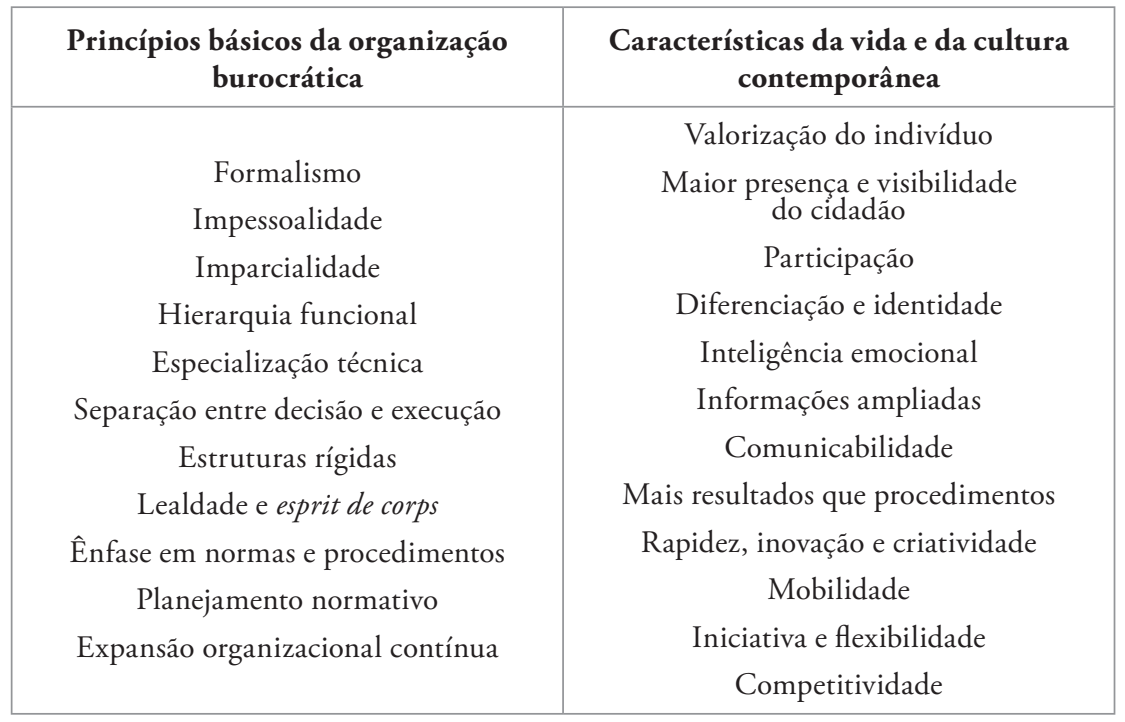

Fonte: Nogueira (2005).

Além disso, a gestão profissional na universidade, pelo menos no que tange a seus servidores, ainda é muito carente de estudos e ações que valorizem mais a integridade humana e que possam contribuir para a formação de quadros mais valorizados, motivados e inclusivos.

Em complemento a isto, Oliveira e Leite (2007) também apontam as dificuldades de encontrar profissionais, especialistas ou gestores que lidem com o gerenciamento da deficiência nas escolas. Em virtude disso, o problema é comum às instituições escolares e ao mercado de trabalho.

\section{Dos resultados}

Embora não tenhamos resultados conclusivos de nossas investigaçóes, que tem como campo uma universidade pública multicampi do Estado de São Paulo, verificou-se junto à Coordenação de Recursos Humanos de sua Reitoria que a mesma segue a Lei Complementar n. 683/1992 (SÃO PAULO, 1992) para seus concursos públicos, na qual está prevista a cota de $5 \%$ das vagas para pessoas com deficiência.

$\mathrm{Na}$ prática, a pessoa com deficiência tem que comprovar sua deficiência e terá direito a realizar a mesma prova do concurso, nas condiçóes que forem necessárias, junto aos demais. A aprovação ocorre por meio da divulgaçáo de duas listas de aprovados, uma de candidatos sem deficiência e outra apenas com os nomes dos candidatos com deficiência aprovados, com isso, pela percentagem 
de 5\% de vagas destinadas ao concurso, uma pessoa com deficiência deve ser chamada, mesmo que o percentual decimal seja menor que 0,5 . Tal legislaçáo está em consonância com a legislação federal.

Para o caso de concurso para docentes, observa-se que não é apresentada nos editais a questáo da reserva de vagas nos concursos, sobretudo porque em muitos casos abre-se apenas uma vaga.

No que tange a outras questóes referentes ao acesso e permanência do servidor público com deficiência, por meio de seu próprio relato na universidade pública, os resultados parciais indicam que os órgãos públicos estão com mais dificuldades em melhor se adaptar às pessoas com deficiências em comparação à esfera privada, e que a administração pública carece de informações básicas de como conhecer a realidade da própria deficiência de seus servidores.

\section{Considerações}

As pessoas com deficiência consolidaram os seus direitos na sociedade brasileira, apesar que, em muitos casos, tal direito ainda tenha que ser reivindicado por força de Lei. No que tange à escola, verifica-se avanços. O mercado de trabalho, por sua vez, como já mencionado, possui uma dinâmica diferente da escola, porém, a relação entre tais instituiçóes é tênue em virtude dos processos produtivos cada vez mais crivados de componentes tecnológicos, de tempos diversos, desregulamentados e flexibilizados.

Entre a esfera pública e a privada há grandes diferenças ao se tratar o tema da inclusão para pessoas com deficiência. Lidar com a inclusão mostra-se um desafio. No caso do setor público, com foco na universidade, o problema se amplia em virtude do desconhecimento das especificidades do público interno em geral e das pessoas com deficiência, em particular.

\section{Referências}

BIZELLI, J. L. Inovação: limites e possibilidades para aprender na era do conhecimento. São Paulo: Editora Unesp/Cultura Acadêmica, 2013. v.1.

BOBBIO, N. A Era dos Direitos. 7. ed. Rio de Janeiro: Campus, 2004.

BRASIL. Constituição (1988). Constituição da República Federativa do Brasil. Brasília, DF: Senado Federal, 1988. Disponível em: http://www.planalto.gov.br/ccivil_03/constituicao/ constituicaocompilado.htm. Acesso em: 8 out. 2014.

BRASIL. Leis e Decretos. Lei n. 8.213, de 24 de julho de 1991. Dispóe sobre os Planos de Benefícios da Previdência Social e dá outras providências. DOU, 25/07/1991, republicado em 11/04/1996 e 14/08/1998. Disponível em: http://www.planalto.gov.br/ccivil_03/leis/ 18213cons.htm. Acesso em: 8 out. 2014. 
BRASIL. Leis e Decretos. Lei n. 9.394, de 20 de dezembro de 1996. Estabelece as Diretrizes e Bases da Educação Nacional. Brasília, DOU, 23/12/1996. Disponível em: http:/www. planalto.gov.br/ccivil_03/leis/19394.htm. Acesso em: 8 out. 2014.

BRASIL. Leis e Decretos. Decreto n. 3.298, de 20 de dezembro de 1999. Regulamenta a Lei n. 7.853, de 24 de outubro de 1989, dispóe sobre a Política Nacional para a Integração da Pessoa Portadora de Deficiência, consolida as normas de proteção, e dá outras providências. DOU, 21/12/1999. Disponível em: http://www.planalto.gov.br/ccivil_03/decreto/d3298.htm. Acesso em: 8 out. 2014.

BRASIL. Leis e Decretos. Lei Federal n. 10.098/2001, de 19 de dezembro de 2000. Estabelece normas gerais e critérios básicos para a promoção da acessibilidade das pessoas portadoras de deficiência ou com mobilidade reduzida, e dá outras providências. Disponível em: http:// www.planalto.gov.br/ccivil_03/leis/l10098.htm. Acesso em: 8 out. 2014.

BRASIL. Leis e Decretos. Decreto n. 6.944, de 21 de agosto de 2009. Estabelece medidas organizacionais para o aprimoramento da administração pública federal direta, autárquica e fundacional, dispóe sobre normas gerais relativas a concursos públicos, organiza sob a forma de sistema as atividades de organização e inovação institucional do Governo Federal, e dá outras providências. DOU, 24/08/2009. Disponível em: http://www.planalto.gov.br/ ccivil_03/_Ato2007-2010/2009/Decreto/D6944.htm\#art32. Acesso em: 14 out. 2014.

CANOTILHO, J. J. G. Direito constitucional e teoria da constituição. Coimbra: Almedina, 1998.

CHIAVENATO, I. Introdução à teoria geral da administração: uma visão abrangente da moderna administração das organizaçôes. Rio de Janeiro: Elsevier, 2004.

FARAH, M. F. S. A contribuição da Administração Pública para a constituição do campo de estudos de políticas públicas. In: MARQUES, E.; FARIA, C. A. P. (Orgs.). A política pública como campo multidisciplinar. São Paulo: Editora Unesp; Rio de Janeiro: Editora Fio Cruz, 2013.

GUGEL, M. A. Pessoas com deficiência e o direito ao concurso público. Goiânia: Editora UCG, 2006.

MAZZOTTA, M. J. S. Educação Especial no Brasil: história e políticas públicas. 5. ed. São Paulo: Cortez, 2005.

MEIRELLES, H. L. Direito administrativo brasileiro. São Paulo: Malheiros Editores, 2001.

MIRANDA, T. G. Trabalho e deficiência: velhos desafios e novos caminhos. In: MANZINI, E. J. Inclusão e acessibilidade. Marília: ABPEE, 2006.

NOGUEIRA, M. A. Sofrimento organizacional, democracia e gestão universitária. In: Gestão universitária. São Paulo: Cultura Acadêmica, 2005. (Série Administraçáo Pública, n. 1).

OLIVEIRA, A. A. S.; LEITE, L. P. Construção de um sistema educacional inclusivo: um desafio político-pedagógico. Ensaio: Avaliação e Políticas Públicas em Educação, Rio de Janeiro, v.15 n.57, p.511-524, out.-dez. 2007. Disponível em: http://www.scielo.br/scielo.php?script= sci_arttext\&pid=S0104-40362007000400004\&lng=en\&nrm=iso. Acesso em: 30 out. 2014.

ONU (Organizanção das Naçôes Unidas). Declaração Universal dos Direitos Humanos. 1948.

ROSS, P. R. Trabalho das pessoas com deficiência: transformando barreiras em oportunidades. In: MANZINI, E. J. Inclusão e acessibilidade. Marília: ABPEE, 2006.

SÃO PAULO. Leis e Decretos. Lei Complementar Estadual n. 683, de 18 de setembro de 1992. Dispóe sobre reserva, nos concursos públicos, de percentual de cargos e empregos para portadores de deficiência e dá providências correlatas. Disponível em: http://www.al.sp.gov.br/repositorio/legislacao/lei.complementar/1992/lei.complementar-683-18.09.1992.html. Acesso em: 8 out. 2014.

SASSAKI, R. K. Inclusão: construindo uma sociedade para todos. Rio de Janeiro: WVA, 2006. 


\section{Resumo}

\section{Acessibilidade e deficiência na universidade: politica de recursos humanos}

Este trabalho é parte integrante de investigação em rede - com apoio da Capes, no Edital Observatório em Educaçâo (Obeduc) - sobre políticas públicas de acessibilidade e inclusão para pessoas com deficiência no Ensino Superior brasileiro. A universidade está despreparada para lidar com a inclusão apesar de existirem muitas políticas específicas para essa finalidade. O campo escolhido para análise foi uma universidade pública do sistema paulista de Educação Superior e, de acordo com os procedimentos metodológicos traçados - que envolveram releitura crítica da bibliografia pertinente, entrevista com gestores universitários, levantamento documental e pesquisa de dados - foi possível verificar grande diferença entre a forma como a esfera pública e a privada tratam o tema da inclusáo para pessoas com deficiência. O desafio no caso estudado se amplia em virtude do desconhecimento das especificidades do público-alvo, melhor dizendo, da falta de conhecimento sobre o funcionário público que trabalha na universidade por sua administração superior. Parte-se de pesquisa bibliográfica, entrevista e levantamento de dados. As discussóes são balizadas em pressupostos de autores da Educação Especial e da administraçáo pública, além da revisão do amparo normativo da legislação federal e estadual, no caso de São Paulo. Consideraçóes: entre a esfera pública e privada há grandes diferenças ao se tratar o tema inclusão para pessoas com deficiência. Lidar com a inclusão mostra-se um desafio e, no caso da universidade, o problema se amplia em virtude do desconhecimento das especificidades desse público.

Palavras-chave: Inclusão. Pessoas com Deficiências. Ensino Superior. Universidade. Mercado de Trabalho. Políticas Públicas.

\section{Abstract}

\section{Accessibility and Disability at the University: Policy of Human Resources}

This essay is part of a network investigation on public policies regarding accessibility and inclusion of people with disabilities in the Brazilian Universities. The university is unprepared to deal with the inclusive process in spite of the many specific policies for this purpose. The chosen field for the analysis was a public university in the state of São Paulo, and the defined methodological procedures - which involves thorough re-reading of the pertinent bibliography, interviews with university management personnel, documentary findings and data research - found great difference in the way the public and the private spheres deal with the inclusion of people with disabilities. The lack of knowledge of the specificities of the target group amplifies the challenge of the case studied, or even the ignorance of the management personnel regarding the university public workers. Bibliographic research, interviews and data findings give us this conclusion. The discussions use as basis Especial Education and Public Administration authors as well as the reviewing of normative legislations, in the case of the state of São Paulo. Considerations: between the public and private spheres there are great differences in dealing with the inclusion of people with disabilities. Dealing with the inclusion poses a challenge and in the case of the university, the problem increases due to the lack of knowledge of the specificities of the target group.

Keywords: Inclusion. People with Disabilities. Higher Education. University. Work. Public Policy Market. 